\title{
Impact of an Educational Session about Premenstrual Syndrome Management Using Complementary and Alternative Medicine on Young Adult females' knowledge and Practice
}

\author{
. Farida Habib ${ }^{(1)}$. Aseel alayed ${ }^{(2),}$ Haifa Al Humedi $^{(3),}$ Ibtehal Al Msalem $^{(4)}$ \\ Maternity Health Nursing Department King Saud bin Abdulaziz University for Health Sciences - Riyadh, \\ Kingdom of Saudi Arabia \\ Undergraduate Nursing Student, College of Nursing, King Saud bin Abdulaziz University for Health Sciences \\ - Riyadh, Kingdom of Saudi Arabia
}

\begin{abstract}
:
Objectives: To assess the impact of educational sessions about PMS management using CAM on young adult females' knowledge and practice Methods: The quasi experimental design was used to conduct the study. The study compromised non probability convenience sample of 201 young adult female nursing students from preprofessional as well as professional years. The sample size was estimated using sample size calculator. Three tools were developed to collect data for this study namely: Sociodemographic questionnaire, pre knowledge and practice assessment tool, and post knowledge and practice assessment tool. A structured session about CAM use in management of PMS was carried out for each subject. The participants were aware about the aim of the study. Verbal agreements (consents) were taken before data collection. Data was coded for entry and analysis using SPSS statistical software package version 18. Results: The mean age of the sample was $21.98+1.23$ years old. About two thirds (66.3\%) of the sample reported that they got their knowledge from family and friends. There was a significant improvement of the subjects' knowledge regarding PMS after the educational session which included definition, time, and symptoms of PMS $(p=0.000$ for each). Also the knowledge of the participants was significantly improved after the educational session regarding CAM use to mange PMS. This included Diet, supplements, herbal, mind body intervention, manipulative and body-based methods ( $p=0.000$ for each). The total knowledge score increased significantly after the educational session $(P=0.000)$. Conclusion: The educational session significantly increased female awareness and practice about PMS.
\end{abstract}

\section{Introduction mad Literature Review}

Remedies and methods of treatment have been inherited by many generations over years. With the aim to decrease coast and side effects of conventional medicine. With medical advances as well as researches, some of these remedies have been given a scientific rationale which drew people's attention and interest toward the usage of these remedies under the name of "Complementary and Alternative Medicine" (Singleton, 2007) .

The CAM can be defined as "Medical and health care practices outside the realm of conventional medicine, which are yet to be validated using scientific methods

The NIH defined CAM as" Healthcare systems, practices, and products not presently considered to be part of conventional medicine (Proctor, 2001)

Women have known for thousands of years that physical and emotional symptoms related to their menstrual cycle occur. Premenstrual syndrome (PMS) is a group of symptoms come and go in relation to the monthly menstrual cycle. PMS can be defined as a disorder that occurs during the luteal phase of the menstrual cycle ( 1 to 2 weeks prior to menses) producing a diverse number of physical and emotional changes (KleinLaansma, 2010)

The most common symptoms of PMS include bloating, backache, breast tenderness, acne, nausea and vomiting, food cravings, fatigue, irritability, and depression, anxiety. These symptoms diminish significantly or disappear completely several days after the onset of menstruation (Cho, 2010 and Jing, 2008)

Nutritional intake and metabolism may play an important role in the cause and treatment of menstrual disorders. Herbal and dietary therapies number among the more popular complementary medicines yet there is a lack of taxonomy to assist in classifying them. Herbs and other phytomedicinal products (medicine from plants) have been legally classified as dietary supplements Vitamins, minerals, herbs or other botanicals, amino acids and other dietary substances are also classified as herbs (Jarvis, 2008).

Lifestyle modifications and exercise are first-line recommendations for all women with PMS/ and may be all that is needed to treat mild-to-moderate symptoms. Herbal and vitamin supplementation and complementary and alternative medicine also help to reduce symptoms of PMS. Women who experience premenstrual breast tenderness can reduce or eliminate this symptom by taking $600 \mathrm{IU}$ of Vitamin E daily. 
Exercise reduces, or sometimes eliminates premenstrual syndrome, and it also is an excellent way to reduce stress and lower risk of diseases including heart disease and cancer (Gepshtein, 2007 and Dvivedi, 2008 )

Nowadays, the usage of CAM to manage PMS is remarkable among Saudi women. However, one of the major reasons cited for the current revival of CAM is the growing awareness of occurrence of side effects due to women misconceptions that these medicines are inherently safer and more healthful. It was hifhly informative to assess the impact of educational sessions about PMS management Using CAM on young adult females' knowledge and awareness in Riyadh, Saudi Arabia.

\section{Research hypothesis:}

Educational sessions about PMS management Using CAM will significantly improve the knowledge of young adult females students

\section{Methodology}

Quasi experimental design was used to conduct this study with the aim to assess the impact of educational sessions about PMS management Using CAM on young adult females' knowledge and awareness in KSAU-HS, Riyadh, Saudi Arabia.

The study compromised a non probability convenience sample of 201 young adult female students, who were enrolled in any health science program. The subjects of the sample were from pre-professional, as well as professional years. The subjects were from college of nursing and college of medicine. The undergraduate female health sciences students' population was estimated to be about 800 students. The sample size was estimated using sample size calculator. With a confidence level of 95 and confidence interval of 6.3 , the sample size was computed to be 185 subjects and it was increased to 201 to insure representativeness of the sample. The students were approached in classrooms after taking the permission of instructors and students to stay longer after the lecture time.

The participants were aware about the aim of the study and they were informed that the participation is voluntary. Verbal agreements (consents) were taken before data collection. The subjects were informed that the data will be anonymous and confidential, and they have the freedom to withdraw from the study any time.

Three tools were developed to collect data for this study. The first tool was Sociodemographic Questionnaire which included data such as age, education and marital status. The second tool was Pre Knowledge and practice assessment tool. This tool had three parts. Part I included 15 questions to assess knowledge of students about PMS such as definition, signs and symptoms. Part II included 25 questions to assess knowledge of students about using CAM to manage PMS symptoms such as diet, exercises, supplement, herbal, body mind interaction and manipulative and Body-based Methods. Part III included 25 questions to assess practice of students about using CAM to manage PMS symptoms such as diet, exercises, supplement, herbal, body mind interaction, manipulative and Body-Based Methods. The third tool was Post Knowledge and practice assessment tool. This tool included the same parts and question in the Pre Knowledge and Practice assessment tool. The first and second tools were applied before the educational session, and the third tool was applied 2 months after the educational session. The pre and post knowledge and practice were scored and the total score was computed for each subject.

The content validity of the instrument was assessed by an expert who examined the tools and approved it. Test retest method was used to determine the reliability of the tool, by applying this tool twice on 5 subjects who were excluded from the study. The reliability was 0.79 . Subjects needed $20-25$ minutes to complete the questionnaire. A pilot study was conducted to test the feasibility and applicability of the tools, and identified the most suitable time to collect data. The pilot study was carried out on five subjects. The result of the pilot study was help in refining the interview questionnaire form.

A structured session about CAM use in management of PMS was carried out for each subject. Each session lasted for $40-45$ minutes. The main objective of the session was to educate students about PMS and how to use Cam to manage its signs and symptoms. The outlines of the session included: define PMS, symptoms and signs of PMS, define CAM, types of CAM, and correct misconceptions

Data was coded for entry and analysis using SPSS statistical software package version 18. Data was presented using descriptive statistics in the form of frequencies and percentages. Interval and ratio variables were presented in the form of means and standard deviations. Paired $t$ test was used to compare the interval and ratio data before and after the session. Wilcoxon Signed Ranks Test was used to compare the ordinal data before and after the session. The significance level was chosen as $(\mathrm{p}<0.05)$. 


\section{Results:}

A total of 226 students did the pre knowledge and pre practice assessment and all of them attended the session. Only 201 students (89\%) completed the post knowledge and practice assessment. We only included the 201 students who completed the pre and post knowledge and practice in the data analysis.

Table 1: Frequency Distribution of the Characteristics of the Subjects in the Sample

\begin{tabular}{|l|c|c|}
\hline Variable & $\begin{array}{c}\text { Number } \\
\mathbf{N = 2 0 1}\end{array}$ & Percent \\
\hline Age & 79 & \\
Less than 20 & 108 & 39.3 \\
$20-22$ & 14 & 53.7 \\
22 and up & 21.98 & 10 \\
Mean & 1.23 & \\
SD & 193 & \\
\hline Marital status & 8 & 96.0 \\
Single & & 4.0 \\
Married & 34 & 16.9 \\
\hline College & 167 & 83.1 \\
Medical & \\
Nursing & \\
\hline
\end{tabular}

As shown in table one the mean age of the sample was $21.98+1.23$ years. About two thirds $(63.7 \%)$ of the students in the sample had age more than 20 years old. The majority (96\%) of the students in the sample were singles. Nursing students were about five times of medical students.

Figure 1: Frequency Distribution of the Subjects' Source of Information about CAM

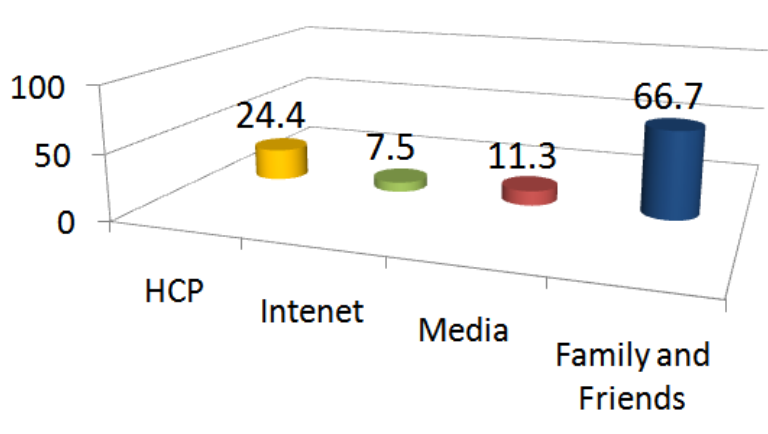

About two thirds of the students got their information about cam form family and friends, but only 24.4 got their information from health care providers.

Table 2: Comparison of the Subjects' Knowledge about PMS before and after the Educational Session

\begin{tabular}{|c|c|c|c|c|c|}
\hline \multirow[t]{2}{*}{ Variables } & \multicolumn{2}{|c|}{ Pre } & \multicolumn{2}{|c|}{ Post } & \multirow[t]{2}{*}{$\mathbf{P}$} \\
\hline & No & $\%$ & No & $\%$ & \\
\hline What is PMS & & & & & 0.000 \\
\hline Correct & 56 & 27.9 & 105 & 52.2 & \\
\hline Wrong & 63 & 31.3 & 39 & 19.4 & \\
\hline Do not know & 82 & 40.8 & 57 & 28.4 & \\
\hline Time of PMS during the Menstrual Cycle & & & & & 0.000 \\
\hline Correct & 43 & 21.4 & 89 & 44.3 & \\
\hline Wrong & 70 & 34.8 & 49 & 24.4 & \\
\hline Do not know & 88 & 43.8 & 63 & 31.3 & \\
\hline
\end{tabular}

Wilcoxon Signed Ranks Test was used to compare the subject's knowledge before and after the session. There was statistically significant improvement in the subjects' knowledge after the educational session regarding the premenstrual syndrome (PMS) definition, and time of PMS during the menstrual cycle $(\mathrm{p}=$ 0.000). The percentage of the subjects who define PMS correctly was almost doubled after the educational session as it was $27.9 \%$ before the session, and it was increased to $52.2 \%$. The percentage of the subjects correctly knew the time of the PMS during the cycle, was increased from $21.4 \%$ before the session to $44.3 \%$ after the session. 
Table 3: Comparison of the Subjects' Correct Knowledge about Physical and Psychological Symptoms of PMS before and after the Educational Session

\begin{tabular}{|c|c|c|c|c|c|}
\hline \multirow[t]{2}{*}{ Variables } & \multicolumn{2}{|c|}{ Pre correct answer } & \multicolumn{2}{|c|}{ Post correct answer } & \multirow[t]{2}{*}{$\mathbf{P}$} \\
\hline & No & $\%$ & No & $\%$ & \\
\hline $\begin{array}{l}\text { Physical Symptoms } \\
\text { Backache } \\
\text { Breast tenderness } \\
\text { Headache } \\
\text { Bowel disturbance } \\
\text { Acne }\end{array}$ & $\begin{array}{l}61 \\
73 \\
66 \\
74 \\
61\end{array}$ & $\begin{array}{l}30.3 \\
36.3 \\
32.8 \\
36.8 \\
30.3\end{array}$ & $\begin{array}{c}86 \\
121 \\
75 \\
100 \\
91\end{array}$ & $\begin{array}{l}42.8 \\
60.2 \\
37.3 \\
49.8\end{array}$ & $\begin{array}{l}0.000 \\
0.000 \\
0.013 \\
0.000 \\
0.000\end{array}$ \\
\hline $\begin{array}{l}\text { Psychological Symptoms } \\
\text { Irritability } \\
\text { Tension } \\
\text { Anxiety } \\
\text { Mood swinging } \\
\text { Depression } \\
\text { Insomnia } \\
\text { Crying }\end{array}$ & $\begin{array}{l}36 \\
50 \\
83 \\
87 \\
79 \\
51 \\
62\end{array}$ & $\begin{array}{l}17.9 \\
24.9 \\
41.3 \\
43.3 \\
39.3 \\
25.4 \\
30.8\end{array}$ & $\begin{array}{c}105 \\
93 \\
135 \\
150 \\
120 \\
100 \\
120\end{array}$ & $\begin{array}{l}52.2 \\
41.3 \\
67.2 \\
74.6 \\
59.7 \\
49.8 \\
59.7\end{array}$ & $\begin{array}{l}0.000 \\
0.000 \\
0.000 \\
0.000 \\
0.000 \\
0.000 \\
0.000\end{array}$ \\
\hline
\end{tabular}

Table 3 showed comparison of the subjects' correct knowledge about physical and psychological symptoms of PMS before and after the educational session. Wilcoxon Signed Ranks Test was used to compare between physical and psychological symptoms before and after the session regarding the physiological symptoms. There was statistically significant improvement after the session in correctly determining the symptoms, which included Backache: breast tenderness, headache, bowel disturbance, and acne $(\mathrm{p}=0.000$, $0.000,0.013,0.000,0.000$ respectively. there was statistically significant improvement after the session in correctly determining the psychological symptoms. The psychological symptoms included irritability, tension, anxiety, mood swinging, depression, insomnia, and crying ( $\mathrm{p}=0.000$ for all symptoms),

Table 4: Comparison of the Subjects' Correct Knowledge about management of PMS symptoms Using CAM before and after the Educational Session

\begin{tabular}{|c|c|c|c|c|c|}
\hline \multirow[t]{2}{*}{ Variables } & \multicolumn{2}{|c|}{ Pre } & \multicolumn{2}{|c|}{ Post } & \multirow[t]{2}{*}{$\mathbf{P}$} \\
\hline & No & $\%$ & No & $\%$ & \\
\hline \multicolumn{6}{|l|}{ Diet } \\
\hline Decrease fat & 13 & 6.5 & 164 & 81.6 & 0.000 \\
\hline Decrease salt & 19 & 9.5 & 187 & 93.0 & 0.000 \\
\hline Decrease species & 25 & 12.4 & 198 & 98.5 & 0.000 \\
\hline Decrease caffeine & 71 & 35.3 & 177 & 88.1 & 0.000 \\
\hline \multicolumn{6}{|l|}{ Supplement } \\
\hline Use Vitamin E & 3 & 1.5 & 145 & 72.1 & 0.000 \\
\hline Use of vitamin B & 4 & 2.0 & 163 & 81.1 & 0.000 \\
\hline \multicolumn{6}{|l|}{ Herbal } \\
\hline Cinnamon & 91 & 45.3 & 198 & 89.5 & 0.000 \\
\hline Mint & 81 & 40.3 & 200 & 99.5 & 0.000 \\
\hline Camion & 56 & 27.9 & 188 & 93.5 & 0.000 \\
\hline Ginger & 53 & 26.4 & 172 & 85.6 & 0.000 \\
\hline \multicolumn{6}{|l|}{ Mind-Body Interaction } \\
\hline Yoga & 26 & 12.9 & 193 & 96.0 & 0.000 \\
\hline Prayer & 84 & 41.8 & 186 & 95.5 & 0.000 \\
\hline Art and music & 27 & 13.4 & 168 & 83.6 & 0.000 \\
\hline \multicolumn{6}{|c|}{ Manipulative and Body-based Methods: } \\
\hline Exercises & 24 & 11.9 & 169 & 84.1 & 0.000 \\
\hline Warm shower & 58 & 28.9 & 182 & 90.5 & 0.000 \\
\hline & 87 & 43.3 & 200 & 99.5 & 0.000 \\
\hline
\end{tabular}

Wilcoxon Signed Ranks Test was used to compare the ordinal data before and after the session. Comparison of the subjects' correct knowledge about management of PMS symptoms Using CAM before and after the educational session, reveled significant improvement of the students' knowledge. There was statistical improvement of the subjects' knowledge after the session on how to use CAM to manage PMS ( $\mathrm{P}=\mathrm{O} . \mathrm{ooo}$ for all) management methods. The majority of the subjects answered the dilatory management correctly after the session which included decrease fat, decrease salt, decrease species and decrease caffeine $(81.6 \%, 93.0 \%$, $98.5 \%$, and $88.1 \%$ respectively). The percentage of the subjects with correct Knowledge regarding use of vitamin E supplements was increased from $1.5 \%$ before the session to $72.1 \%$ after the session. Also for Vitamin B supplement the correct answers was increased from $2 \%$ to $88.1 \%$ after the session. Regarding herbs the percent of subjects with correct answers was almost doubled as Cinnamon and Mint and almost trebled for Carmon and Ginger. The majority of the subject got the correct answers after the educational session regarding 
using mind body interaction to manage the PMS symptoms. The mind body interaction included yoga, prayer, art and music.

Figure 2; Comparison of the Subjects' Total Knowledge Score about CAM before and after the Educational Session

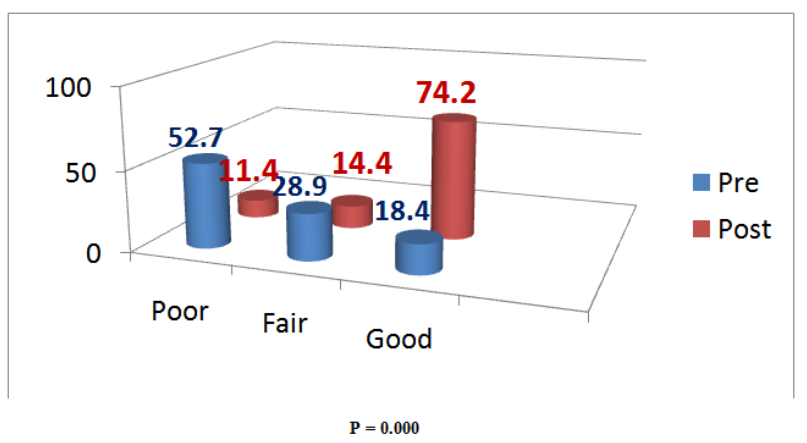

There was a significant improvement in the total knowledge score after the educational session than before the session $(\mathrm{p}=0.000)$. The mean knowledge score was 42.43 before the session while it was 83.45 after the session. Fifty two point seven percent of the subjects had poor knowledge before the session, compared to only $31.4 \%$ after the session. Before the session the percentage of the subjects with good knowledge was only $18.4 \%$ compared to $72.2 \%$ after the session

Table 5: Comparison of the Subjects' Correct Practices for management of PMS symptoms Using CAM before and after the Educational Session

\begin{tabular}{|c|c|c|c|c|c|}
\hline \multirow[t]{2}{*}{ Variables } & \multicolumn{2}{|c|}{ Pre } & \multicolumn{2}{|c|}{ Post } & \multirow[t]{2}{*}{$\mathbf{P}$} \\
\hline & No & $\%$ & No & $\%$ & \\
\hline \multicolumn{6}{|l|}{ Diet } \\
\hline Decrease fat & 7 & 3.5 & 29 & 14.4 & 0.000 \\
\hline Decrease salt & 3 & 1.5 & 73 & 36.3 & 0.000 \\
\hline Decrease species & 13 & 6.5 & 83 & 41.3 & 0.000 \\
\hline Decrease caffeine & 0 & 0 & 63 & 31.3 & 0.000 \\
\hline \multicolumn{6}{|l|}{ Supplement } \\
\hline Use Vitamin E & 0 & 0 & 4 & 4.5 & 0.046 \\
\hline Use of vitamin B & 0 & 0 & 9 & 8.5 & 0.003 \\
\hline \multicolumn{6}{|l|}{ Herbal } \\
\hline Cinnamon & 15 & 7.5 & 123 & 61.2 & 0.000 \\
\hline Mint & 34 & 16.9 & 89 & 44.3 & 0.000 \\
\hline Camion & 12 & 6.0 & 102 & 50.7 & 0.000 \\
\hline Ginger & 6 & 3 & 74 & 36.8 & 0.000 \\
\hline \multicolumn{6}{|l|}{ Mind-Body Interaction } \\
\hline Yoga & 0 & 0 & 5 & 2.5 & 0.014 \\
\hline Prayer & 0 & 0 & 65 & 42.3 & 0.000 \\
\hline Art and music & 0 & 0 & 6 & 3 & 0.025 \\
\hline \multicolumn{5}{|c|}{ Manipulative and Body-based Methods: } & \\
\hline Exercises & 2 & 1.0 & 21 & 10.4 & 0.000 \\
\hline Warm shower & 5 & 2.5 & 8 & 4.9 & 0.083 \\
\hline & 3 & 1,3 & 34 & 16.9 & 0.000 \\
\hline
\end{tabular}

Wilcoxon Signed Ranks Test was used to compare the ordinal data before and after the session. Comparison of the subjects' practice for management of PMS symptoms Using CAM before and after the educational session reveled significant increase in the percentages of the students using CAM to manage their menstrual symptoms. There was a statistical increase in the number of the subjects in using diet, supplements, mind body interaction and herbs to mange PMS symptoms ( $p=0.000$ for all diet and herbal management items). More students decreased fat, salt, spices and coffee. Also more students used Cinnamon, Mint, Camion, and Ginger. Regarding supplement. There was significant increase in the subjects in use vitamin E and B ( $p=0.046$, $p=0.003)$. There were no significant changes in the subjects practice of excurses $(p=0.83)$. 


\section{Figure 3: Comparison of the Subjects' Total Practice Score about CAM before and after the Educational} Session

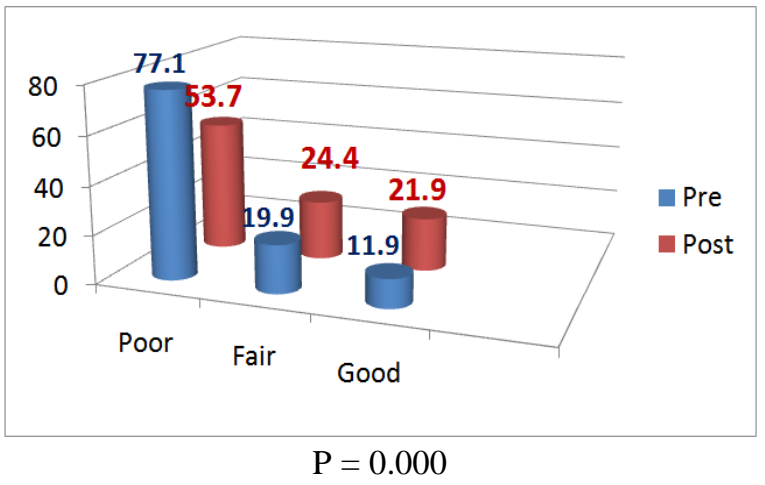

There was a significant improvement in the total practice score after the educational session than before the session $(\mathrm{p}=0.000)$. The mean practice score was 21.38 before the session, while it was 61.25 after the session. Seventy seven point one percent of the subjects had poor practice before the session compared to only $53.7 \%$ after the session. Before the session the percentage of the subjects with good practice was only $11.9 \%$ compared to $21.9 \%$ after the session

\section{Discussion}

A structured educational session for 45 minutes was conducted to 201 health sciences college students. The session focused on teaching students about PMS and how to manage its symptoms using CAM. The baseline data knowledge and practice were assessed before the session and knowledge and practice post test were done after the session

In the current study about $37.3 \%$ of the subjects used at least one form of complementary and alternative medicine to manage symptoms of PMS before the intervention. This percent was increased to about 67.2\% after the intervention. This results was in agreement with a study by Domoney (2003), he found that $91 \%$ of women had used at least one form of complementary therapy for the management of their premenstrual symptomatology although only $35 \%$ were current users.

Choi (2010), found that Most of the women (91.5\%) had no knowledge regarding terminology pertaining to PMS. In the current results was obtained as about half (52\%) of the subjects in the sample had poor knowledge about PMS. This result could be obtained because the subjects in the sample were college female students who are enrolled in any college in the health field (Nursing, Medical). The subjects might had a prior knowledge about PMS.

The herbal was the most common method that the subjects used after intervention. The four herbs used by the subjects in a descending percent were Cinnamon, Camion, Mint, and Ginger

Yassin (2012) Studded "Herbal Remedy used by Rural Adolescent girls with Menstrual Disorders". The results showed that Premenstrual syndrome (PMS) was experienced by $77.7 \%$ of the study subjects $72.7 \%$ of them had used herbal remedy for treatment. The type of herbs used in management of PMS and dysmenorrhea were fenugreek, peppermint and aniseed which were effective among almost all of the study subjects. Green tea, cinnamon and basil were moderately effective

The method that used mostly next to herb was prayer. Although the difference between pre and post intervention practice of the subjects regarding use of vitamin supplementation, Yoga, and art and music was statistically significant but the percent of increase was not effective

A Case -control Study conducted by Chocano-Bedoya, (2011) discussing the " Dietary B vitamin intake and incident premenstrual syndrome" .they observed a significantly lower risk of PMS in women with high intakes of thiamine and riboflavin from food. In the current study the majority of the subjects did not change their dilatory practice. Only $14.4 \%$ reduced fat in their diet, while $31.3 \%$ decreased coffee intake, salt was decreased by $33.6 \%$ and species was reduced by $41.3 \%$ of the subjects.

Sveinsdóttir (1991) concluded that, women responded to their symptoms by taking some time to relax, take pain medication, or seek support. Women experiencing more severe symptoms were more likely to seek support from a partner, relative, or friend

Conduct an awareness campaign to raise the Saudi female about PMS management.

Replicate the study on different sample with increasing the session's number and assess their practice

Healthcare providers need to be aware of the symptoms of PMS and the treatment options available. Treatment selection should be based on individual patient symptoms, concomitant medical history, and need for contraception. 
It is important to improve awareness of these therapies, both in qualitative and quantitative terms. Satisfaction with prescribed medications did not appear to be influenced by complementary therapy use in this group of women. Farther studies about the effectiveness of the cam on management of PMS should be conducted

\section{Funding} profit sectors.

This research received no specific grant from any funding agency in the public, commercial, or not-for

\section{Conflict of Interest}

Researchers declare no conflict of interest with any organization regarding the materials discussed in this manuscript

\section{References}

[1] Cho SH, Kim J. Efficacy of acupuncture in management of premenstrual syndrome: a systematic review. Complement Ther Med. 2010 Apr;18(2):104-11. doi: 10.1016/j.ctim.2009.12.001. Epub 2010 Mar 17.

[2] Chocano-Bedoya PO, Manson JE, Hankinson SE, Willett WC, Johnson SR, Chasan-Taber L, Ronnenberg AG, Bigelow C, BertoneJohnson ER. Dietary B vitamin intake and incident premenstrual syndrome. Am J Clin Nutr. 2011 May;93(5):1080-6. doi: 10.3945/ajcn.110.009530. Epub 2011 Feb 23.

[3] Dvivedi J, Dvivedi S, Mahajan KK, Mittal S, Singhal A. Effect of '61-points relaxation technique' on stress parameters in premenstrual syndrome. Indian J Physiol Pharmacol. 2008 Jan-Mar;52(1):69-76.

[4] Domoney CL, Vashisht A, Studd JW. Use of complementary therapies by women attending a specialist premenstrual syndrome clinic. Gynecol Endocrinol. 2003 Feb;17(1):13-8.

[5] Gepshtein Y, Plotnikoff GA, Watanabe K. Kampo in women's health: Japan's traditional approach to premenstrual symptoms. J Altern Complement Med. 2008 May;14(4):427-35. doi: 10.1089/acm.2007.7064.

[6] Klein-Laansma CT, Jansen JC, van Tilborgh AJ, Van der Windt DA, Mathie RT, Rutten AL. Semi-standardised homeopathic treatment of premenstrual syndrome with a limited number of medicines: feasibility study. Homeopathy. 2010 Jul;99(3):192-204. doi: 10.1016/j.homp.2010.05.007.

[7] Jarvis CI, Lynch AM, Morin AK. Management strategies for premenstrual syndrome/premenstrual dysphoric disorder. Ann Pharmacother. 2008 Jul;42(7):967-78. doi: 10.1345/aph.1K673. Epub 2008 Jun 17.

[8] Jing Z, Yang X, Ismail KM, Chen X, Wu T. Chinese herbal medicine for premenstrual syndrome. ochrane Database Syst Rev. 2009 Jan 21;(1):CD006414. doi: 10.1002/14651858.CD006414.pub2.

[9] Proctor ML, Murphy PA. Herbal and dietary therapies for primary and secondary dysmenorrhoea. Cochrane Database Syst Rev. 2001;(3):CD002124.

[10] Singleton G. Premenstrual disorders in adolescent females-- integrative management.

[11] Australian Family Physician. 2007 Aug;36(8):629-30.

[12] Sveinsdóttir H, Marteinsdóttir G. Retrospective assessment of premenstrual changes in Icelandic women. Health Care Women Int. 1991 Jul-Sep;12(3):303-15.

[13] Yassin. A.A. Herbal Remedy used by Rural Adolescent girls with Menstrual Disorders. Journal of American Science, 2012;8(1) 